which was to prove in later years such a wide-spread and sightdestroying scourge.

\title{
REFERENCES
}

BoldT.- "Trachoma." Translated by J. H. Parsons and T. Snowball. London. 1914.

Collins.- Introduction to Boldt (above).

Cuénod et Nataf.- "Le Trachome," 1930.

DUKE-ELDER.-Text-book of Ophthalmology. Vol. II. London. 1938.

EASON.-(1) Trans. Ophthal. Soc. U.K., p. 38, 1918. (2) Guy's Hospital Reports, Vol. LXX, p. 63.

EBLE.- "Die ... agyptische Augenentzundung." Stuttgart. 1839.

FUCHS (DUANE). - Text-book of Ophthalmology. Eighth edition. 1924.

LARREY.- " Memories de Chirurgie Militaire et Campagnes." Paris. 1812.

MACCALlan.- "Trachoma." London, 1936, and private communication.

MEYERHOF. - Brit. Jl. Ophthal, p. 129, 1932.

VETCH.-(1) "A Practical Treatise on the Diseases of the Eye." London. 1820.

(2) "An Account of the Ophthalmia which has appeared in England since the return of the British Army from Egypt. London. 1807. (3) Observations relative to the Treatment by Sir William Adams of the Ophthalmic Cases of the Army." London. 1818.

\section{OCULAR CHANGES ASSOCIATED WITH NAEVUS FLAMMEUS}

BY

\author{
J. Jameson Evans and P. JAMEson Evans \\ BIRMINGHAM
}

THE influence of maldevelopment of the orbital vessels upon the optic nerve has been widely discussed in recent years. Many types of malformation, localised to various sites in the globe and orbit, have been described, and their existence in association with intra-cranial and facial lesions noted (notably by Lindau, ${ }^{9}$ Lawford, ${ }^{8}$ Cushing $^{3}$ and $\mathrm{Knapp}^{6}$ ). The question of whether optic atrophy, with cupping, so often found in such cases, is the result of true glaucoma with tension or, maybe, a primary atrophy due to a disturbance of the nutrition of the nerve, and in which the intra-ocular tension is not, of itself, a factor of importance, is still undecided. It may be recalled that Schnabel ${ }^{13}$ strongly advocated the view that, even in true glaucoma with increased tension, the cupping of the optic disc was independent of the state of the intraocular tension and was due to an essential lacunar atrophy of the optic nerve. In association with haemangiomatosis, and other malformations of the vessels of the eye and orbit, Löwenstein, ${ }^{10}$ Bär, ${ }^{1}$ McRae, ${ }^{11}$ and $\mathrm{O}^{\prime}$ Brien and Porter $^{12}$ report instances where there has been no demonstrable rise of tension: on the other hand the majority of cases of this type of lesion have been associated with an increased intra-ocular tension and, bearing in mind 
that the volume of the intra-ocular contents in such cases is especially subject to sudden increase, this is only to be expected.

Further, such malformation, affecting the vascular coat of the eye, is often found to be associated with other changes in this layer (abnormal development of the filtration angle, etc.), so that abnormalities of tension are to be expected. Indeed, it would appear that little more proof is available that increase of tension results in optic atrophy than that the reverse process is true. Thiel $^{15}$ has recently drawn attention to instances of optic atrophy with cupping, indistinguishable from that of chronic primary glaucoma, but without tension, in which sclerosis of the internal carotid arteries is held to be the basic factor. $\mathrm{Knapp}^{6}$ also has published a series of cases of this type in which sclerosis of the basal cerebral vessels was a constant finding.

In the present paper two cases are submitted for consideration : the one showing increase of tension, the other with normal tension over a number of years of observation. Both are instances of naevus flammeus with associated ocular changes.

Case 1. P.R.E., aged 23 years. When first observed in 1931, presented an extensive naevus flammeus of the whole face extending up to the hair line and some distance down the neck. The mouth and palate were also involved; the reason for wishing an ophthalmic examination was recurrent inflammation of the left eye. This was of the nature of a patch of superficial vascular keratitis in the upper and outer quadrant of the cornea, the resultant nebulae involving a part of the pupillary area.

The intra-ocular findings in this eye, as also in the right eye in which the cornea was normal, were a pronounced development of reddish tortuous vessels in the iris stroma which appeared slightly thickened, and of the circulus minor, and of bunches of tortuous vessels in the neighbourhood of the filtration angle. The media were clear and there was no suggestion of opacities in the lens or vitreous. The pupil reflexes were normal; the anterior chamber was of normal depth in each eye. The optic discs were deeply cupped, about three-fourths of the discs being involved, and the cupped area showed distinct pallor. The retinal vessels were not definitely abnormal in size, but they were rather tortuous. Vision was normal in the right eye, but in the left vision was only $6 / 24$ owing to corneal opacity and irregularity of surface. The fields showed temporal contraction to $20^{\circ}-30^{\circ}$, more marked in the left field. There was, during observation, no variation of intra-ocular tension, which was normal, and at no time was an increase of tension noted, or the probability of it suggested by symptoms or observation. Schiötz $18 \mathrm{~mm}$. Hg in each eye.

The attacks of keratitis in the left eye recurred once or twice a year and the duration of the attacks was generally about fourteen 
days. They were associated with some increase of vascularity of the nasal mucous membrane, and there were indications of left antral infection in February, 1934.

During 1934 an attempt was made to cure the facial naevus by means of massive doses of radium by surface applications to the neck and radon needles in the lips. In 1935 the patient complained of impairment of vision in both eyes. At this time no material change was noticeable in the external appearance of the eyes, but there was slight but definite fibrosis, with some decoloration, of the facial angioma. The lips, however, became more congested and oedematous, showing a tendency to partial necrosis. The dilated and tortuous vessels in the iris were less obvious and showed definite sclerosis. The pupil reflexes were still normal. X-rays of the skull at this time showed enlarged and tortuous vessels of the meninges and a circular calcareous area in the occipital pole of the brain. The lenses showed the posterior cortical cataract, saucer-like in type, commonly seen in glass-blowers and known as ray cataract. The other media and the fundi were unchanged. Vision-R.E. $=6 / 18$, L.E $:=6 / 36$. The use of atropine to improve vision had no effect on the tension which remained unchanged. The cataract was regarded as being the result of the heavy radium therapy. This view is supported by $\mathrm{Mr}$. Harrison Butler and $\mathrm{Mr}$. Stallard, whose observations are appended. At present, the lenticular opacities appear to be stationary. The facial deformity is now being treated by plastic surgery.

Case 2. A.C., aged 12 years. Attended the Birmingham and Midland Eye Hospital with pain in the left eye of three weeks' duration, and the history that the eye had been blind since birth and that it had previously given pain on a number of occasions. Right Eye-vision 6/6, this eye was normal in every respect. Left Eye-vision, no perception of light. Tension $42 \mathrm{~mm}$. $\mathrm{Hg}$ Schiötz. There was congestion of the conjunctival and anterior ciliary vessels. The cornea was oedematous; the anterior chamber shallow, with a small hyphaema below: the iris vessels prominently coursing over the anterior surface. The lens showed a diffuse intumescent cataract. Transillumination gave an even but rather dim reflex.

The face showed a left sided naevus flammeus, confined to the approximate limits of the skin distribution of the maxillary division of the fifth nerve, but overlapping the ophthalmic area a little. The mucous membranes of the cheek, palate and soft palate on this side were involved.

Other parts of the body presented areas of skin haemangioma. A full neurological investigation showed no evidence of lesions involving the central nervous system. X-rays of the skull showed no areas of abnormal calcification, but the left optic foramen was slightly larger than the right. 
A provisional diagnosis was made of secondary glaucoma due to intra-ocular haemorrhage resulting from the presence of haemangioma of the choroid.

The eye was removed the next day, without excessive bleeding, and the diagnosis was confirmed by pathological examination.



FIG. 1 (a).



FIG. $1(b)$.



FIG. 2 . 
The microscopic study of the eye revealed a flat growth of haemangiomatous tissue of the choroid occupying the posterior third of the globe's circumference: the retina was completely detached and the sub-retinal space occupied by recent haemorrhage. No vitreous existed, the detached retina forming a doublelayered fold in the centre of the globe (Fig. 1). The optic disc was deeply cupped (Fig. 2) and the nerve greatly atrophied and



FIG. 3.

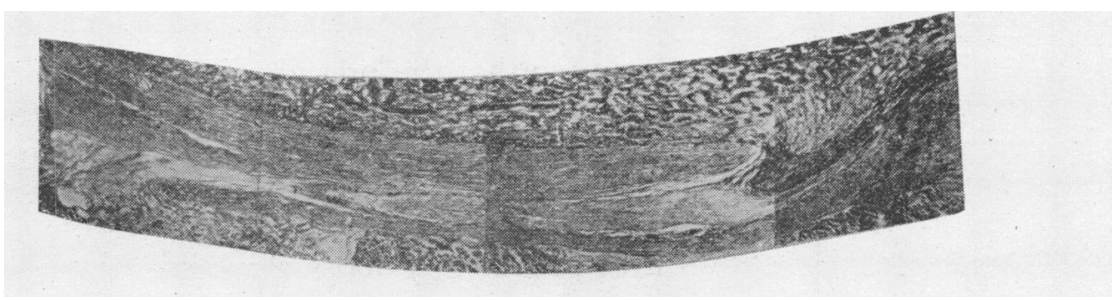

FIG. 4.

presenting, in addition to small haemorrhages, many spaces of lacunar atrophy. The filtration angle of the anterior chamber was quite closed by the forward displacement of the iris and lens. The growth itself consisted of a flat wide thickening of the choroid occupying the posterior pole of the globe, very similar to that described by Jahnke ; the enormous distension of the vessels is

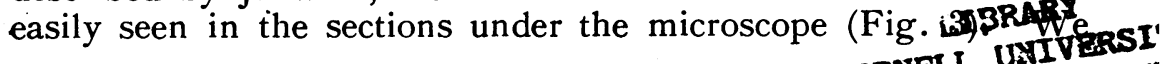


were particularly fortunate in being able to demonstrate the course of the communication of the intra-ocular tumour through the sclera to the extra-ocular veins, the track following the path of the vorticose vein (Fig. 4). This suggests that the growth itself is essentially derived from the venous side of the vascular tree and not from the arterial, an observation which may have some bearing on the co-existence, in some cases, of areas showing calcareous degeneration in the occipital lobe and elsewhere. Recent work on venous stasis has emphasised its important bearing on the failure of metabolism in the tissues.

This case has already been reported in the American Archives of Ophthalmology (August, 1937) as an instance of haemangioma of the choroid (but the question of optic atrophy was not then fully discussed), and is described again by courtesy of the editor of that journal.

In respect of the second case (A.C.) the optic atrophy is very advanced and the cupping deep. What is the mechanism of the cupping of this case? That there was a raised intra-ocular tension on several occasions may be presumed by the history of recurrent attacks of pain extending over a number of years. That which brought the patient to our notice was apparently similar to its predecessors, though more severe in degree. The diagnosis of intraocular haemorrhage being the cause of the increased tension was confirmed by the findings in the excised eye, and, from the degenerated appearance of the retina and its completely detached condition, leaving practically no true vitreous space (Fig. 1). It is reasonable to suppose that such retro-retinal haemorrhages had caused the previous attacks of pain. Hence, one cannot hold that increased pressure in the vitreous space had produced cupping of the disc directly. Moreover, the detached retina is not pressed down into the disc although it lies directly in front, being firmly attached at the disc margin, so that the pressure from retro-retinal haemorrhage would not appear to be responsible. It is suggested then that the cupping is the result of primary atrophy of the nerve consequent upon impaired nutrition, associated with the abnormal state of the blood vessels supplying the nerve. The histology of the nerve also shows a comparatively loose structure, in no way conveying the impression of compression, and in which are found, not only spaces filled with blood, but others suggestive of lacunar atrophy. However, since this case has been complicated by repeated attacks of raised intra-ocular tension the thesis is not indisputable.

Turning, therefore, to the first case in which there is deep cupping, with pallor of the discs; increased tension has never been noted during a period of seven years under observation, nor have there ever been symptoms which might suggest increased 
intra-ocular pressure. In fact the tonometric readings have never reached $20 \mathrm{~mm}$. $\mathrm{Hg}$ (Schiötz); and up to the time of the unfortunate formation of (radium) cataract there had been no appreciable alteration in visual fields or acuity.

In Knapp's ${ }^{7}$ report of optic atrophy with cupping, associated with sclerosis of the basal cerebral vessels, the average age of the patients is 65 years. While some degree of senile change of vessels is to be expected at such an age, the changes are not usually sufficiently advanced to be demonstrable by plain X-ray photographs of the skull. In many cases of naevus flammeus the sclerotic and degenerative changes (frequently with some amount of calcification) are so marked as to be easily demonstrable by $\mathrm{X}$-ray in young patients, whilst in those cases showing homonymous hemianopic field changes (D. Campbell, ${ }^{2} \mathrm{H}$. Tyson ${ }^{16}$ ) as a result of the presence of a haemangioma in the occipital lobe of the brain, there are obvious patches of calcareous degeneration.

Cushing and Bailey ${ }^{4}$ have commented upon the tendency of venous angiomata to undergo calcification. The incidence of occipital angiomata in these cases appears to be more than fortuitous, but the governing factors are at present entirely unknown.

Thiel ${ }^{15}$ also has published a number of cases in which atrophy and cupping of the optic disc, indistinguishable from that of glaucoma, has occurred in association with sclerosis of the internal carotid vessels and without increase of the intra-ocular pressure, he has further demonstrated the presence of nasal field defects in such cases.

In the second case (A.C.) no sclerosis of intra-cranial vessels was observed, but in the first.(P.R.E.) there is marked opacity of the internal carotid and middle meningeal vessels and, in addition, a sharply defined calcareous area in the occipital region (but without any hemianopia in the fields). This sclerosis constitutes a sign of defective nutrition of the vessel walls and provides evidence also in favour of a similar defect in the nutrition of the tissues supplied by these vessels-among which is included the optic nerve.

It might be expected that, in such cases, the lens, dependent as it is for its transparency on adequate nourishment from the surrounding fluids and hence, indirectly, on the state of the vessels of the uveal tract, would be affected and that cataract would be commonly found. This, however, does not appear to be the case either in Knapp's series of ten cases or in those cases of haemangioma retinae described by Lindau. In other cases the incidence of cataract is complicated by the presence of buphthalmos, etc. 
Hence, in the second case the formation of cataract may have been due to the sudden increase of tension and to its effect on the passage of oxygen through the lens capsule. Evidence in favour of this is found in the intumescent and diffuse character of the cataract, giving the impression of recent development.

In the first case the cataract is of a very different nature. When first seen this case presented no opacity of the lens in either eye, the opacities developing some two months after the institution of radium therapy (1934) to the face and lips with which their incidence appears to be closely related.

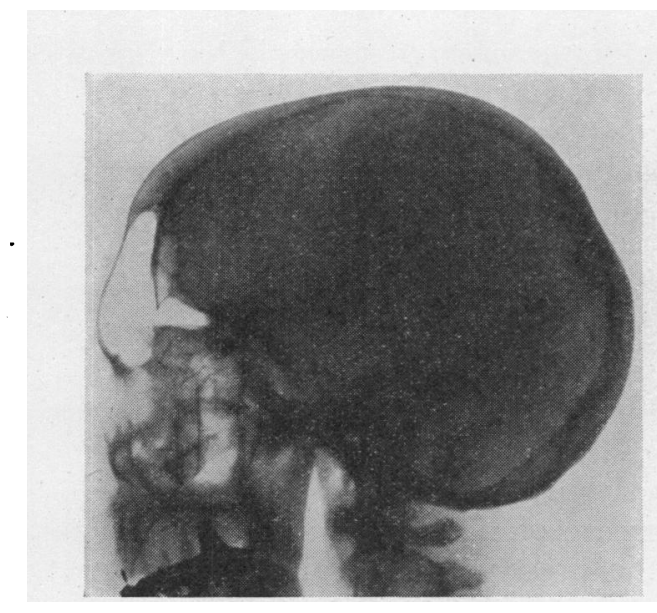

FIG. $5(a)$

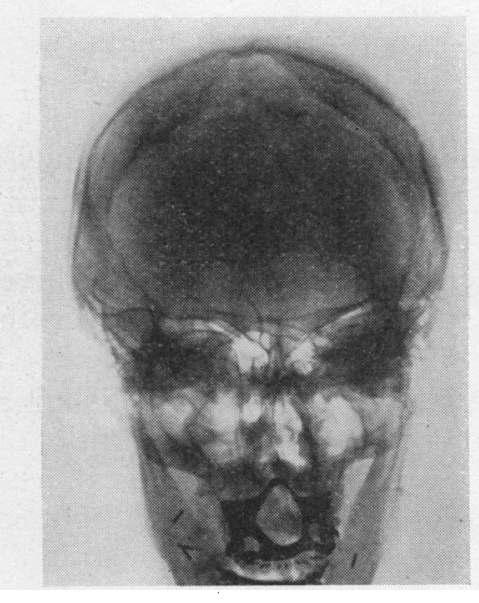

FIG. $5(b)$

Reduced X-ray diagrams of skull of P.R.E.

(a) Lateral view. (b) Antero-posterior view.
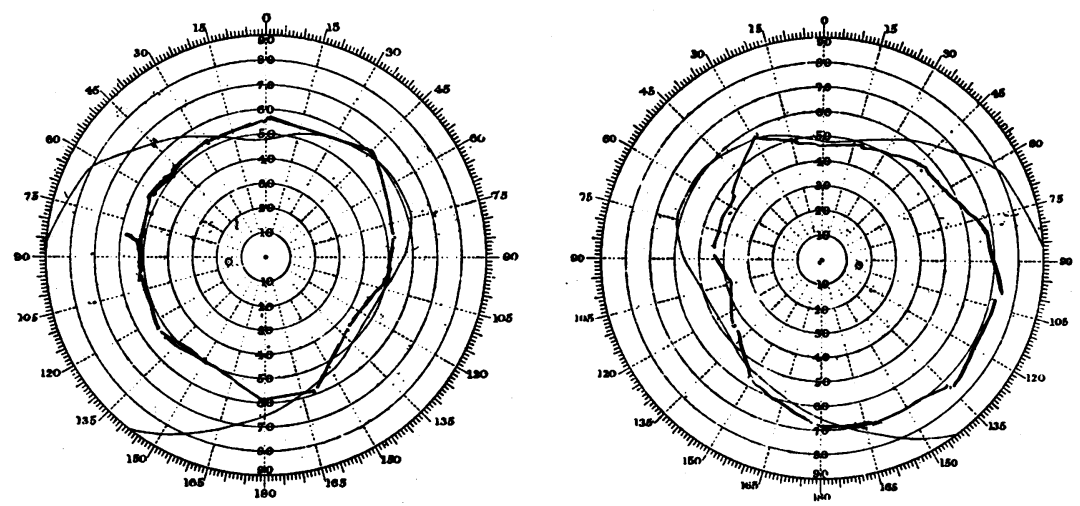

FIG. $6(a)$

January 5, 1935 ,

FIG. $6(b)$ 



FIG 6. (c)

July 27, 1938.

FIG. $6(d)$

P.R.E. Fields of Vision $\left(\frac{1}{2}^{\circ}\right.$ white).

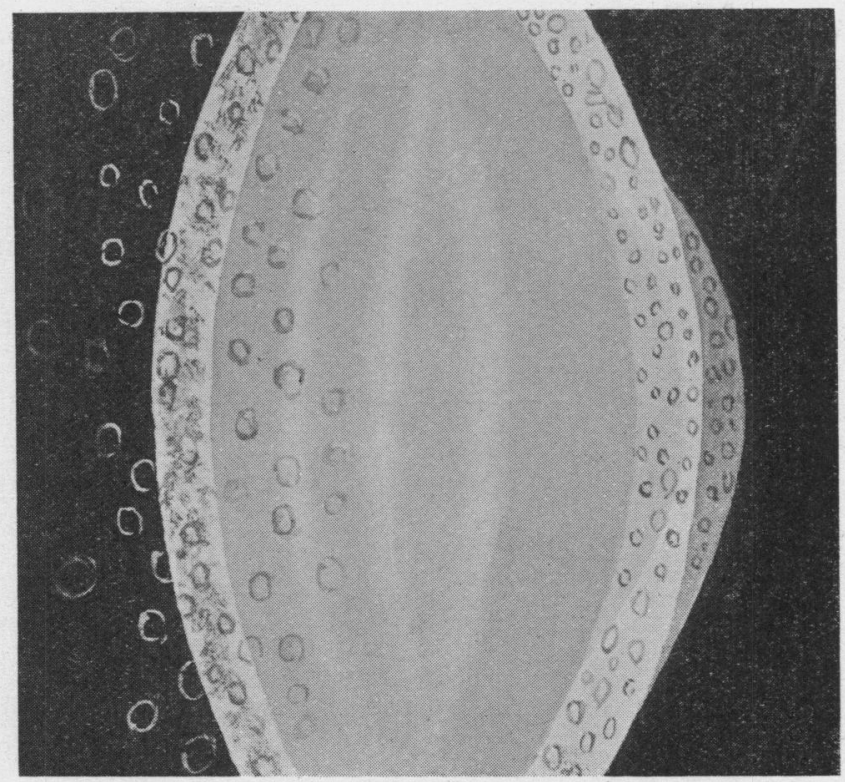

FIG. $7(a)$

Drawing of the lens seen with the broad beam of the slitlamp: showing the split appearance of the posterior capsule with bulging of the posterior layer giving the appearance of a lenticonus posterior : also the vacuolation.

(By courtesy of Mr. T. Harrison Butler.) 


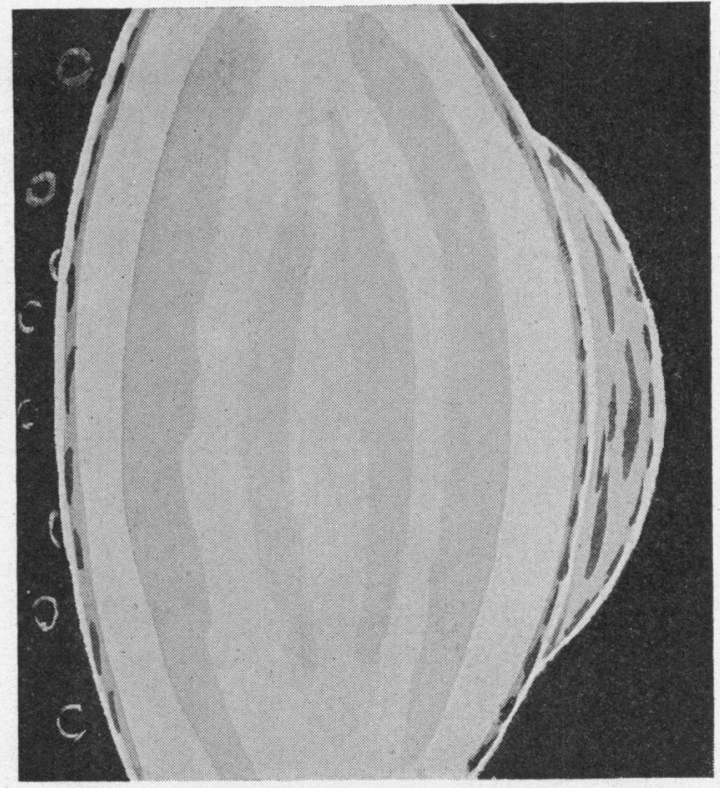

We are indebted to Mr. Harrison Butler for comments upon the slit-lamp appearances of the lens. "Under each anterior capsule there are a number of large vacuoles. The anterior lens shagreen is more easily seen, and is of a coarser type than in the normal lens. The posterior capsule appears to be split, giving an appearance similar to that seen in lenticonus posterior. The cortex in front of each of these posterior layers of capsule is vacuolated, but the vacuoles are smaller than those seen in the anterior part of the lens.

"The lens matter between the split capsules is also vacuolated. There is a double vacuolated layer (Figs. $7(a)$ and $7(b))$. The appearances correspond closely with those of X-ray cataract described by $\operatorname{Vog}^{17},{ }^{18}$ but in this case the posterior bulge and double layer are more pronounced. There is no doubt whatsoever that this condition is caused by the radium treatment."

Further, Mr. H. B. Stallard, who gave an opinion on this case, also considered the lens opacities to be the result of the radium therapy. He writes that "the lens changes in the posterior layers of the cortex are typical of irradiation cataract and have probably been caused by the heavy dosage of radium two years 
ago." This authority further remarks " the optic discs are deeply cupped but, in the absence of increased intra-ocular pressure and field loss, I presume this is a congenital defect and associated with intra-ocular vascular abnormalities."

Hence, it seems fairly certain that this case does, in fact, present an instance, of which other examples are quoted in Mr. Stallard's monograph on the subject ${ }^{14}$ of delayed cataract formation resulting from irradiation. Such cases are rare, but perhaps are destined to become more common with the greater frequency of radium therapy.

\section{Summary and Conclusions}

Two cases associated with optic atrophy and other changes are reported of naevus flammeus. It is held that the optic atrophy follows upon defective nutrition of the nerve resulting from abnormal vascular supply, and is not secondary to, nor dependent upon, a rise of intra-ocular tension.

In the one case there was increased intra-ocular tension on at least one, and probably on several, occasions during a long history ; in the other case no increase of tension has been observed during a period of thirteen years. It is held that, certainly in the latter case, and possibly in the former also, optic atrophy is independent of changes in the intra-ocular pressure.

The second case presents the rare opportunity of microscopic examination of a haemangioma of the choroid and particularly of the course of entry of the haemangiomatous tissue into the globe. The first case shows the presence of associated intracranial vascular abnormalities and of irradiation cataract.

\section{BIBLIOGRAPHY}

1. B̈̈R, C.-Zeitschr. f. Augenheilk., Vol. LVII, p. 628, 1925.

2. CAMPBELL, D. C.-Personal communications, 1937.

3. Cushing, H.-Jl. Amer. Med. Assoc., Vol. XLVII, p. 178, 1906

4. Cushing, H. and Balley, P.-Springfield, Illinois (C. Thomas), 1928.

5. JAHNKE, W.-Zeitschr. f. Augenheilk., Vol. LXXIII, p. 219, 1931.

6. KNAPP, A.-Arch of Ophthal., Vol. LVII, p. 219, 1928.

7. Idem.-Arch. of Ophthal.. Vol. LXV, p. 637, 1932

8. LAWFor D, J. B-Trans. Ophthal. Soc. U.K., Vol. V, p. 136, 1885.

9. LINDAU, A.-Acta Ophthal., p. 193, 1927.

10. LöWEnStein, A.-Klin. Monatsbl. f. Augenheilk., Vol. LXX, p. 540, 1923.

11. MCRaE, A.-Brit. Jl. Ophthal., Vol. XIII, p. 63, 1929.

12. O'Brien and Porter.-Arch. of Ophthal., Vol. LXVI, p. 715, 1933.

13. Schnabel.-Arch. $f$. Augenheilk., Vol. XXIV, p. 273, 1892.

14. Stallard, H. B.-Radiant Energy. Monograph Supplement, Brit. Jl. of Ophthal., 1933.

15. THIEL, P. J.-Röntgendiagnostik des Schädels bei Erkrankungen : des Auges und seiner Nachbarorganen. Pp. 134-143. 1932. (Julius Springer, Berlin).

16. Tyson, H. H.-Arch. of Ophthal., Vol. VIII, p. 365, 1932.

17. VoGT, A. -Spaltlampenmicroscopie. Vol. II, p. 709. 1931.

18. Idem.-Spaltlampenmicroscopie. Vol. II, p. 712-714. 1931. 